Received: 15 May 2017

Accepted: 22 August 2017

Published online: 14 September 2017

NTIFIC REPRTS

\title{
Thermal properties of
}

$\mathrm{Zn}_{2}\left(\mathrm{C}_{8} \mathrm{H}_{4} \mathrm{O}_{4}\right)_{2} \bullet \mathrm{C}_{6} \mathrm{H}_{12} \mathrm{~N}_{2}$ metalorganic framework compound and mirror symmetry violation of dabco molecules

\author{
Svetlana G. Kozlova $\mathbb{1}^{1,2}$ \& Svyatoslav P. Gabuda ${ }^{1}$ \\ Thermal properties of $\mathrm{Zn}_{2}\left(\mathrm{C}_{8} \mathrm{H}_{4} \mathrm{O}_{4}\right)_{2} \bullet \mathrm{C}_{6} \mathrm{H}_{12} \mathrm{~N}_{2}$ metal-organic framework compound at 8-300 K suggest \\ the possibility of subbarrier tunnelling transitions between left-twisted (S) and right-twisted (R) forms \\ of $\mathrm{C}_{6} \mathrm{H}_{12} \mathrm{~N}_{2}$ dabco molecules with $\mathrm{D}_{3}$ point symmetry. The data agree with those obtained for the \\ temperature behavior of nuclear spin-lattice relaxation times. It is shown that there is a temperature \\ range where the transitions are stopped. Therefore, $\mathrm{Zn}_{2}\left(\mathrm{C}_{8} \mathrm{H}_{4} \mathrm{O}_{4}\right)_{2} \bullet \mathrm{C}_{6} \mathrm{H}_{12} \mathrm{~N}_{2}$ and related compounds are \\ interesting objects to study the effect of spontaneous mirror-symmetry breaking and stabilization of \\ chiral isomeric molecules in solids at low temperatures.
}

Chirality-related interactions are demonstrated by chiral molecules, i.e. those that can exist in both left- and right-handed forms. According to molecular quantum mechanics, such molecules appear in their ground state which is a symmetrical superposition of these two chiral states. However, biological systems are asymmetric (superselection phenomenon) due to fundamental parity violations ${ }^{1-3}$ or the concept of environmental decoherence $^{4-6}$. As it was discussed earlier, it would be of interest to study the stabilization of chiral molecules in solids at low temperatures to simulate the conditions of the cold scenario ${ }^{7}$. However, the expected fundamental conclusions are still not supported by detailed analysis of the interactions within crystal structures where the stabilization effect is not suppressed by other impacts ${ }^{8,9}$. In this respect, of high interest are metal-organic framework compounds with large pores, open internal channels, and large internal surface areas ${ }^{10-12}$.

One such typical example is $\mathrm{Zn}_{2}\left(\mathrm{C}_{8} \mathrm{H}_{4} \mathrm{O}_{4}\right)_{2} \bullet \mathrm{C}_{6} \mathrm{H}_{12} \mathrm{~N}_{2}$ crystal. It is composed of tetragonal layers of zinc terephthalic acid $\mathrm{Zn}\left(\mathrm{C}_{8} \mathrm{H}_{4} \mathrm{O}_{4}\right)$ linked by 1,4-diazabicyclo[2.2.2] octane molecules $\left(\mathrm{C}_{6} \mathrm{H}_{12} \mathrm{~N}_{2}\right.$, or dabco). Dabco molecules have three isomeric forms: one untwisted form with $\mathrm{D}_{3 \mathrm{~h}}$ symmetry, one left-twisted $(\mathrm{S})$ and one right-twisted (R) form with $\mathrm{D}_{3}$ symmetry each (Fig. 1). Dabco molecules are dynamically disordered around the $c$ axis of $\mathrm{Zn}_{2}\left(\mathrm{C}_{8} \mathrm{H}_{4} \mathrm{O}_{4}\right)_{2} \bullet \mathrm{C}_{6} \mathrm{H}_{12} \mathrm{~N}$ crystal. The distance between them is $\sim 7 \AA$, so they have no direct contacts with each other $^{11}$.

According to our calculations of isolated dabco molecules, their degenerate energy states correspond to twisted $D_{3}(S)$ and $D_{3}(R)$ forms, and the energy barrier $\left(E_{a}\right)$ between these two states can vary between 0 and $0.36 \mathrm{~kJ} / \mathrm{mol}$ depending on the external conditions ${ }^{13}$. Consequently, $\mathrm{D}_{3}(\mathrm{~S}) \leftrightarrow \mathrm{D}_{3}(\mathrm{R})$ transforms can happen as: (1) barrier-free transitions; (2) activation transitions to overcome the barrier; (3) subbarrier tunnelling transitions. Low activation barrier $\mathrm{E}_{\mathrm{a}}$ between $\mathrm{D}_{3}(\mathrm{~S})$ and $\mathrm{D}_{3}(\mathrm{R})$ forms makes prospective studying tunnelling transitions between these forms, in contrast to those between $\mathrm{L}$ - and $\mathrm{D}$-forms of amino acids in solids with $\mathrm{E}_{\mathrm{a}} \sim 300 \mathrm{~kJ} / \mathrm{mol}$ barrier?.

The untwisted $\mathrm{D}_{3 \mathrm{~h}}$ state of the dabco molecule corresponds to its transition state and therefore its energy is equal to the value of the energy barrier $\mathrm{E}_{\mathrm{a}}$ (Fig. 1) ${ }^{13}$. However, this state can be stable in crystals, and the untwisted molecule can move using both the activation and the tunnelling mechanisms.

${ }^{1}$ Nikolaev Institute of Inorganic Chemistry, Siberian Branch of the Russian Academy of Sciences, Academician Lavrentiev Avenue 3, 630090, Novosibirsk, Russian Federation. ${ }^{2}$ Novosibirsk State University, Pirogova Street 2, 630090 , Novosibirsk, Russian Federation. Svetlana G. Kozlova and Svyatoslav P. Gabuda contributed equally to this work. Correspondence and requests for materials should be addressed to S.G.K. (email: sgk@niic.nsc.ru) 

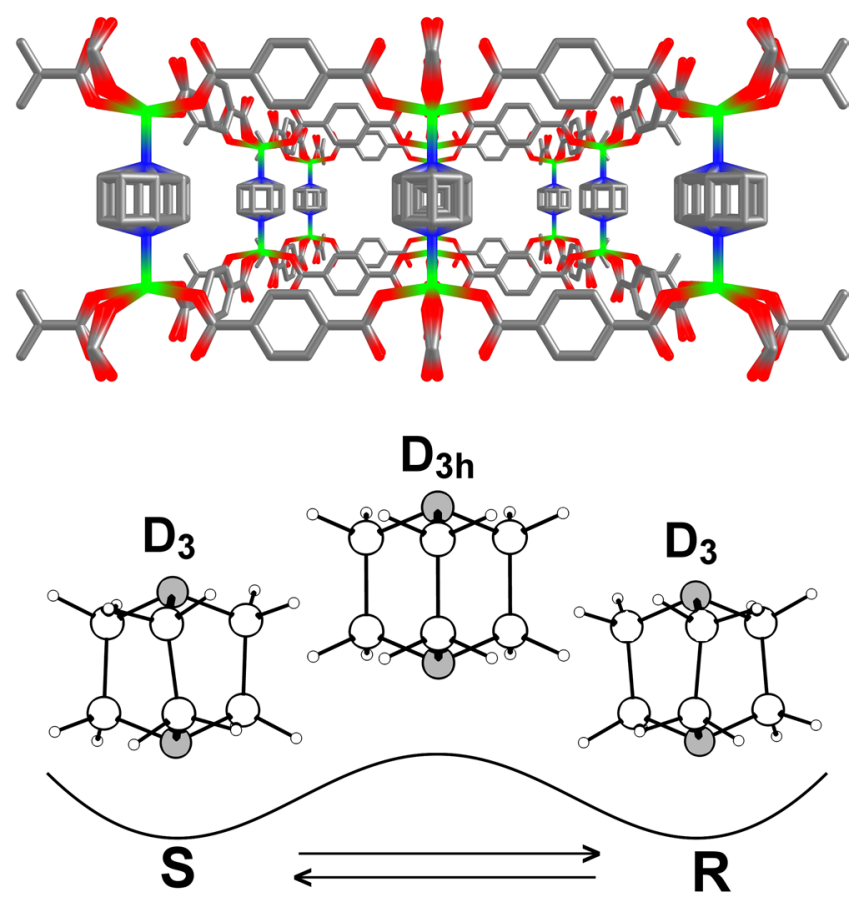

Figure 1. Crystal structure of $\mathrm{Zn}_{2}\left(\mathrm{C}_{8} \mathrm{H}_{4} \mathrm{O}_{4}\right)_{2} \bullet \mathrm{C}_{6} \mathrm{H}_{12} \mathrm{~N}_{2}$, space group $P 4 / m m m ; a=10.93, c=9.61 \AA$; $\mathrm{Z}=1$; $\mathrm{T}=223 \mathrm{~K}^{11}$. Pillar dabco molecules are shown as dynamically disordered (top). Left- and right-twisted $\mathrm{D}_{3}$ and untwisted $\mathrm{D}_{3 \mathrm{~h}}$ conformations of dabco molecules (bottom).

As it was discovered earlier, there are three phase transitions in $\mathrm{Zn}_{2}\left(\mathrm{C}_{8} \mathrm{H}_{4} \mathrm{O}_{4}\right)_{2} \bullet \mathrm{C}_{6} \mathrm{H}_{12} \mathrm{~N}_{2}{ }^{14-16}$. Temperature behavior of spin-lattice relaxation times studied with ${ }^{1} \mathrm{H} N M R \mathrm{~T}_{1}$ demonstrates the effects of tunnelling transitions starting between $\mathrm{D}_{3}(\mathrm{~S})$ and $\mathrm{D}_{3}(\mathrm{R})$ forms of dabco molecules at $\sim 165 \mathrm{~K}$, the violation of these transitions at $\sim 60 \mathrm{~K}$, and substantial difference between the values of spin-lattice relaxation data for dabco conformers at $<25 \mathrm{~K}$. In this work we analyze thermal energies of dabco molecules in $\mathrm{Zn}_{2}\left(\mathrm{C}_{8} \mathrm{H}_{4} \mathrm{O}_{4}\right)_{2} \bullet \mathrm{C}_{6} \mathrm{H}_{12} \mathrm{~N}_{2}$ to show that these effects are thermally possible.

\section{Theoretical background}

Over-barrier transitions (activation) are characterized by the correlation time

$$
\tau_{\mathrm{a}}=\tau_{\mathrm{a} 0} \cdot \exp \left(\frac{\mathrm{E}_{\mathrm{a}}}{\mathrm{k}_{\mathrm{B}} \cdot \mathrm{T}}\right),
$$

where $\mathrm{k}_{\mathrm{B}}$ is the Boltzmann constant, $\tau_{\mathrm{a} 0}$ is the pre-exponential factor for the Arrhenius law, $\mathrm{T}$ is the temperature.

Subbarrier tunnelling is described by the Shrödinger equation and is characterized by the correlation time

$$
\tau_{\mathrm{t}}=\tau_{\mathrm{t} 0} \cdot \exp \left[\frac{2 \mathrm{~L}}{\hbar} \sqrt{2 \mathrm{~m}\left(\mathrm{E}_{\mathrm{a}}-E\right)}\right],
$$

where $\mathrm{m}$ is the mass of the tunnelling particle, $\tau_{\mathrm{t} 0}$ is the pre-exponential factor for tunnelling transitions (inverse vibrational frequency of the particle in the potential well), $\mathrm{E}$ is the kinetic (thermal) energy of the particle, $\mathrm{L}$ is the width of the activation barrier, $\mathrm{h}$ is the Planck constant.

As is well known, thermal energy of atoms and molecules is determined by the temperature of the solid and can be calculated as $\mathrm{E}=\mathrm{C}_{\mathrm{p}} \cdot \mathrm{T}$, where $\mathrm{C}_{\mathrm{p}}$ is the thermal capacity of the solid at constant pressure.

In solids, thermal energy is unevenly distributed between atoms and molecules, and at each moment the amplitude and the energy of thermal vibrations for some part of particles can be higher or lower than their average values. To make the transitions possible, some thermal energy is needed. Activation transitions require that some part of particles have $\mathrm{E}>\mathrm{E}_{\mathrm{a}}$, while tunnelling transitions proceed $\mathrm{E} \mathrm{E}<\mathrm{E}_{\mathrm{a}}$.

We assume that tunneling and activation transitions have the same reaction coordinate. Then for tunnelling transitions with reaction coordinate coinciding with that of reorientational motion (maintaining $\mathrm{D}_{3 \mathrm{~h}}$ and $\mathrm{D}_{3}$ symmetries), the minimum distances between the atoms are $\mathrm{D}^{\mathrm{H}}=1.08 \AA$ (for hydrogen atoms) and $\mathrm{D}^{\mathrm{C}}=0.65 \AA$ (for carbon atoms). For tunnelling transitions between $\mathrm{D}_{3}(\mathrm{~S})$ and $\mathrm{D}_{3}(\mathrm{R})$ these distances are $\mathrm{D}^{\mathrm{H}}=0.66 \AA$ and $\mathrm{D}^{\mathrm{C}}=0.15 \AA^{13}$. Both $\mathrm{D}^{\mathrm{C}}$ values are smaller than the covalent radius of the carbon atom $\left(\mathrm{r}^{\mathrm{C}} \sim 0.70 \AA\right)$. Hence, we can assume that carbon atoms change their positions during tunnelling without having to overcome a barrier. $\mathrm{D}^{\mathrm{H}}$ values exceed the covalent radius of the hydrogen atom $\left(\mathrm{r}^{\mathrm{H}} \sim 0.30 \AA\right)$. In this case, the barrier has finite width $\mathrm{L}$ and reaches its minimum of $\sim 0.06 \AA$ for tunnelling transitions between $\mathrm{D}_{3}(\mathrm{~S})$ and $\mathrm{D}_{3}(\mathrm{R})$ dabco forms. The 

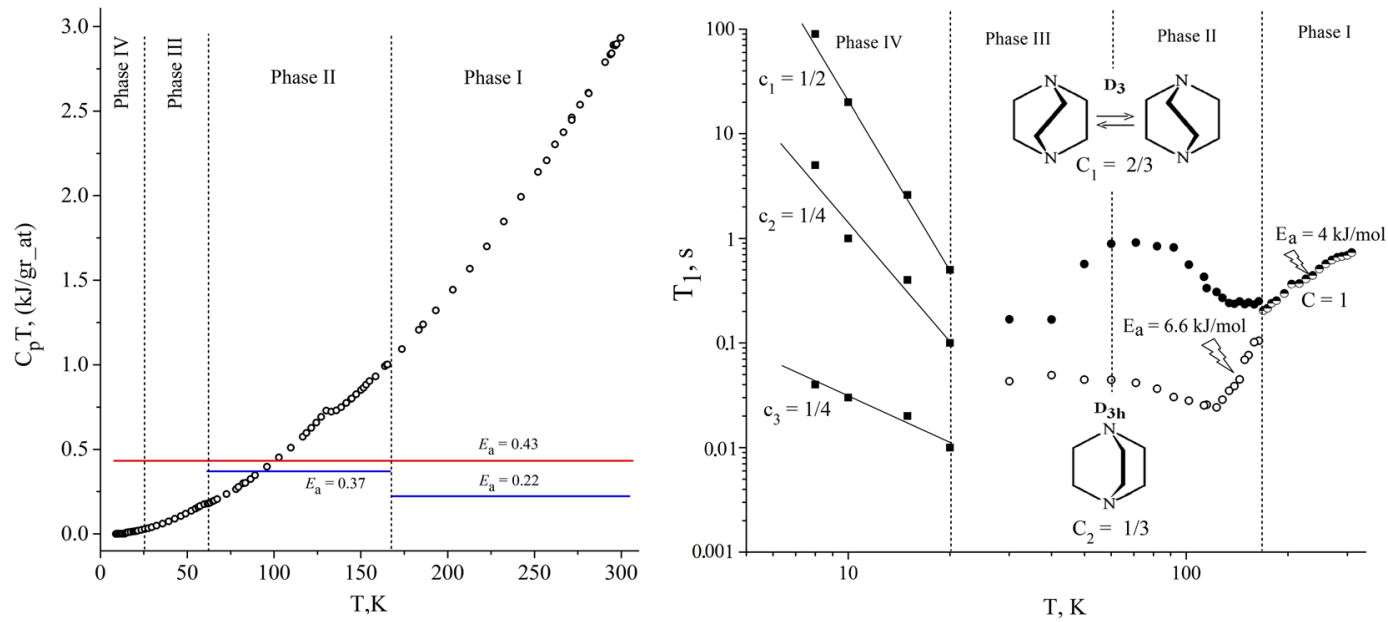

Figure 2. Left: temperature dependence of the thermal energy $\mathrm{C}_{\mathrm{p}} \cdot \mathrm{T}$ in $\mathrm{Zn}_{2}\left(\mathrm{C}_{8} \mathrm{H}_{4} \mathrm{O}_{4}\right)_{2} \bullet \mathrm{C}_{6} \mathrm{H}_{12} \mathrm{~N}_{2}$ (o). Red horizontal line corresponds to the activation barrier $\left(E_{\mathrm{a}}\right)$ between energy minima of $\mathrm{D}_{3}(\mathrm{~S})$ and $\mathrm{D}_{3}(\mathrm{R})$ forms of dabco molecules. Blue horizontal lines correspond to the experimental activation barriers $\left(E_{\mathrm{a}}\right)$ obtained for the reorientation of dabco molecules in Phases I and II. Right: temperature dependence of ${ }^{1} \mathrm{H} \mathrm{NMR} \mathrm{T}_{1}$ in $\mathrm{Zn}_{2}\left(\mathrm{C}_{8} \mathrm{H}_{4} \mathrm{O}_{4}\right)_{2} \bullet \mathrm{C}_{6} \mathrm{H}_{12} \mathrm{~N}_{2}$ presented in the double logarithmic scale. $\mathrm{C}, \mathrm{C}_{\mathrm{i}}$ and $\mathrm{c}_{\mathrm{i}}(\mathrm{i}=1,2,3)$ are the fractions of the components in the FID. $\mathrm{E}_{\mathrm{a}}$ are experimental activation barriers for the reorientation of dabco molecules. Vertical dashed arrows indicate the position of phase transition temperatures according to NMR data ${ }^{14-16}$.

comparison of distances between hydrogen and carbon atoms for both types of tunnelling transitions suggests that the tunneling between twisted forms has the highest probability.

The activation barrier between these two forms in $\mathrm{Zn}_{2}\left(\mathrm{C}_{8} \mathrm{H}_{4} \mathrm{O}_{4}\right)_{2} \bullet \mathrm{C}_{6} \mathrm{H}_{12} \mathrm{~N}_{2}$ crystal is unknown. Moreover, the width and the height of the activation barrier fluctuate due to thermal vibrations. They can change when the temperature decreases and consequently affect the tunneling processes. Nonetheless, the value of the parabolic barrier can be estimated as ${ }^{7}$ :

$$
\mathrm{E}_{\mathrm{a}}=2 \mathrm{~m}\left(\mathrm{~T}_{\mathrm{c}} \cdot \mathrm{k}_{\mathrm{B}} \cdot \mathrm{L} \cdot \pi / \hbar\right)^{2}=7.7 \mathrm{~kJ} / \mathrm{mol},
$$

where $T_{c}$ is the onset temperature of the tunnelling processes (in our case, $165 \mathrm{~K}$ ) ${ }^{14-16}, \mathrm{~L}=0.06 \AA$, and $\mathrm{m}$ is the particle mass. In our case, $m$ is the sum of masses of 12 hydrogen atoms. Carbon atoms can be excluded because of their barrier-free motion, and nitrogen atoms are not involved in tunnelling transitions because they are located along $\mathrm{C}_{3}$ axis of the dabco molecule.

\section{Results and Discussion}

Figure 2 presents temperature dependence $\mathrm{C}_{\mathrm{p}} \cdot \mathrm{T}$, where $\mathrm{C}_{\mathrm{p}}$ is the thermal capacity of $\mathrm{Zn}_{2}\left(\mathrm{C}_{8} \mathrm{H}_{4} \mathrm{O}_{4}\right)_{2} \bullet \mathrm{C}_{6} \mathrm{H}_{12} \mathrm{~N}_{2}$ obtained in ref. 17. The same figure shows $E_{\mathrm{a}}$ values for dabco molecules. Values $E_{\mathrm{a}}=0.22 \mathrm{~kJ} / \mathrm{gr} \_$at and $E_{\mathrm{a}}=0.37 \mathrm{~kJ} / \mathrm{gr}$ _at correspond to experimental values $\mathrm{E}_{\mathrm{a}}=4.0 \mathrm{~kJ} / \mathrm{mol}$ and $\mathrm{E}_{\mathrm{a}}=6.6 \mathrm{~kJ} / \mathrm{mol}$, and $E_{\mathrm{a}}=0.43 \mathrm{~kJ} / \mathrm{gr}$ _at corresponds to the calculated $\mathrm{E}_{\mathrm{a}}=7.7 \mathrm{~kJ} / \mathrm{mol}$, respectively. $E_{\mathrm{a}}$ values are assumed to correspond to activation energies only of hydrogen and carbon atoms of the dabco molecule, and nitrogen atoms are not involved in the reorientation. All values of $\mathrm{C}_{\mathrm{p}} \cdot \mathrm{T}$ and $\mathrm{E}_{\mathrm{a}}$ were normalized to one gram-atom to make easier comparison of the results obtained from different methods.

Since in Phase I thermal energy $\mathrm{C}_{\mathrm{p}} \cdot \mathrm{T}>0.43>0.22 \mathrm{~kJ} / \mathrm{gr}$ at, above $\mathrm{T}_{\mathrm{c}}$ all dabco conformers can overcome barriers $E_{\mathrm{a}}=0.43 \mathrm{~kJ} / \mathrm{gr}$ at and $E_{\mathrm{a}}=0.22 \mathrm{~kJ} / \mathrm{gr}$ at through the activation mechanism, which agrees with $\mathrm{T}_{1} \mathrm{NMR}$ data (Fig. 2). The temperature dependence of ${ }^{1} \mathrm{H} N M R \mathrm{~T}_{1}$ in $\mathrm{Zn}_{2}\left(\mathrm{C}_{8} \mathrm{H}_{4} \mathrm{O}_{4}\right)_{2} \bullet \mathrm{C}_{6} \mathrm{H}_{12} \mathrm{~N}_{2}$ at $310-165 \mathrm{~K}$ obeys the classical theory of nuclear spin-lattice relaxation and is characterized by a single-exponential recovery of the free induction decay (FID) $)^{18,19}$. The activation mobility of dabco molecules is characterized by one barrier $\mathrm{E}_{\mathrm{a}}=4 \mathrm{~kJ} / \mathrm{mol}$ and $\tau_{\mathrm{a} 0}=1.1 \cdot 10^{-14} \mathrm{~s}$. It means that in Phase I either two twisted forms and one untwisted form of dabco molecules are indistinguishable in their energies, or that the system has only one of three conformations (e.g., untwisted) as energetically excited ${ }^{14,16}$.

Thermal energy $\mathrm{C}_{\mathrm{p}} \cdot \mathrm{T}$ varies in Phase II from 1.0 to $0.2 \mathrm{~kJ} / \mathrm{gr}$ at. These thermal energies make it impossible for all particles to overcome the barrier with $E_{\mathrm{a}}=0.43 \mathrm{~kJ} / \mathrm{gr}$ at by the activation mechanism, as well as the barrier $E_{\mathrm{a}}=0.37 \mathrm{~kJ} / \mathrm{gr}$ at. Hence, this phase suggests tunnelling transitions. Indeed, at $165-60 \mathrm{~K}$ the activation mobility of particles is violated. Firstly, the double-exponential recovery of FID is observed ${ }^{14,16}$. The contribution of FIDs characterized by longer time $\mathrm{T}_{1}{ }^{\mathrm{L}}$ and shorter time $\mathrm{T}_{1}{ }^{\mathrm{S}}$ to the total magnetization are $\mathrm{C}_{1}=2 / 3$ and $\mathrm{C}_{2}=1 / 3$, respectively. This double-exponential recovery of FID may indicate that activation mobility of dabco molecules is hindered and that energy states of their conformers become different. From the obtained $C_{1}$ and $C_{2}$ values we can conclude that the energy states were equally stabilized for each conformer. Since $D_{3}(S)$ and $D_{3}(R)$ forms are characterized by the same time $\mathrm{T}_{1}{ }_{1}^{\mathrm{L}}$, they are indistinguishable in energy. These dabco molecules can make tunnelling transitions under the barrier $\mathrm{E}_{\mathrm{a}}=7.7 \mathrm{~kJ} / \mathrm{mol}$. Their states are energetically more favorable than those of the untwisted form. This follows from the fact that if molecules are distributed over their energy states in crystals according to the Boltzmann 
statistics, then the energy population for the untwisted form $\left(\mathrm{C}_{2}\right)$ in $\mathrm{Zn}_{2}\left(\mathrm{C}_{8} \mathrm{H}_{4} \mathrm{O}_{4}\right)_{2} \bullet \mathrm{C}_{6} \mathrm{H}_{12} \mathrm{~N}_{2}$ turns out to be lower than that of two twisted forms $\left(\mathrm{C}_{1}\right)$. The conclusion correlates with quantum chemical calculations which show that the untwisted form of a free dabco molecule $\left(D_{3 h}\right.$ symmetry) is its transition state ${ }^{13}$. Secondly, in the range $165-120 \mathrm{~K} \mathrm{~T}_{1}{ }^{\mathrm{L}}$ is virtually temperature independent, which indicates tunnelling transitions ${ }^{14,16}$. The $\mathrm{T}_{1}^{\mathrm{S}}$ behavior at these temperatures corresponds to the activation process with $\mathrm{E}_{\mathrm{a}}=6.6 \mathrm{~kJ} / \mathrm{mol}$ and $\tau_{\mathrm{a} 0}=0.3 \cdot 10^{-14} \mathrm{~s}$. Therefore, untwisted molecules continue to participate in activation transitions. Below $100 \mathrm{~K}$ dabco molecules are capable mostly of tunnelling transitions, since $\mathrm{C}_{\mathrm{p}} \cdot \mathrm{T}<0.37 \mathrm{~kJ} / \mathrm{gr}$ _at. Therefore, the structure of untwisted dabco molecules cannot correspond to the stable state and must get its symmetry lower.

As follows from Fig. 2, in Phase III tunnelling transitions are possible. On the other hand, due to possible asymmetry of the double-well potential for $\mathrm{D}_{3}(\mathrm{~S})$ and $\mathrm{D}_{3}(\mathrm{R})$ forms the transitions can be stopped. This is indicated by the behavior of anomalous part of the heat capacity of $\mathrm{Zn}_{2}\left(\mathrm{C}_{8} \mathrm{H}_{4} \mathrm{O}_{4}\right)_{2} \bullet \mathrm{C}_{6} \mathrm{H}_{12} \mathrm{~N}_{2}$ at the second order phase transitions $\sim 60 \mathrm{~K}^{20}$. Below $\sim 60 \mathrm{~K}$, the anomalous part of the specific heat demonstrates exponential behavior, which suggests tunnelling of less stable right-enantiomers into more stable left-enantiomers (Salam model) $2,3,20$.

In Phase IV, thermal energy is $\mathrm{C}_{\mathrm{p}} \cdot \mathrm{T} \leq 0.02 \mathrm{~kJ} / \mathrm{gr}_{\text {a }}$ at. In this case, only tunnelling transitions are possible, and, according to equation (2), time $\tau_{t}$ must reach its highest value here. However, the behavior of $\mathrm{T}_{1}$ (Fig. 2) does not correspond to classical views on tunnelling processes ${ }^{7,21,22}$. $\mathrm{T}_{1}$ grows when the temperature decreases (like $\mathrm{T}_{1}$ during activation transitions). But there is no consistent activation mobility of the particles neither. Experimental data on time dependences of FID for these temperatures makes it possible to distinguish at least three components $\left(c_{1}, c_{2}, c_{3}\right)$ characterized by three different $T_{1}$ values (Fig. 2). This can mean that $D_{3}(S)$ and $D_{3}(R)$ energies are not equal at the lowest temperatures and that the system as a whole must be characterized by chiral polarization $^{14-16}$. The discovered difference between $\mathrm{T}_{1}$ times can be considered as an analogue of the previously discovered effect when the multiplicity of the NMR spectrum is doubled when passing from a optically inactive (racemic) to optically active mixtures of chiral isomers ${ }^{23,24}$.

As was shown earlier, the mechanism of phase transition from Phase III to Phase IV in our model can be associated with the ordered packing of untunnelling and non-reorienting $\mathrm{D}_{3}(\mathrm{~S})$ and $\mathrm{D}_{3}(\mathrm{R})$ dabco molecules ${ }^{14-16}$. In this case, violation of $D_{3}(S) \leftrightarrow D_{3}(R)$ symmetry can be due to random factors similar to those affecting the precipitation of R-and S-forms of optically active crystals from racemates ${ }^{25}$. However, the fact that there are three values $\mathrm{c}_{1}, \mathrm{c}_{2}$, and $\mathrm{c}_{3}$ (Fig. 2) obtained from the analysis of FID suggests some ambiguity of the proposed model. We can assume that further temperature decrease should lead to further phase transitions and molecular ordering. Also, some additional mechanism to cause non-exponential FID and nuclear spin-lattice relaxations is also possible ${ }^{16}$.

Note that we do not consider here the mobility of $\mathrm{C}_{8} \mathrm{H}_{4} \mathrm{O}_{4}{ }^{2-}$ anions, because their high activation barrier $(>36 \mathrm{~kJ} / \mathrm{mol}$ ) makes them perform only slow reorientations about the second-order axis. There are no fluctuations of intramolecular dipole-dipole interactions, the fluctuations of intermolecular dipole-dipole interactions are small, and reorientation of $\mathrm{C}_{8} \mathrm{H}_{4} \mathrm{O}_{4}{ }^{2-}$ anions is not evidenced by ${ }^{1} \mathrm{H}$ NMR $\mathrm{T}_{1}$ measurements ${ }^{14,26-28}$.

\section{Conclusions}

Thermal properties of $\mathrm{Zn}_{2}\left(\mathrm{C}_{8} \mathrm{H}_{4} \mathrm{O}_{4}\right)_{2} \bullet \mathrm{C}_{6} \mathrm{H}_{12} \mathrm{~N}_{2}$ crystals suggest that there is a possibility that mirror symmetry can be violated between $\mathrm{D}_{3}(\mathrm{~S})$ and $\mathrm{D}_{3}(\mathrm{R})$ forms of dabco molecules. Most interesting are the lowest temperatures where all conformers can be stabilized in their local positions.

Structural transformations associated with the ordering of dynamically disordered dabco molecules in $\mathrm{Zn}_{2}\left(\mathrm{C}_{8} \mathrm{H}_{4} \mathrm{O}_{4}\right)_{2} \bullet \mathrm{C}_{6} \mathrm{H}_{12} \mathrm{~N}_{2}$ during phase transitions can, in principle, be characterized using the approaches described in refs 29 and 30 . Here we can only describe the structures expected in different phases. In the high-temperature Phase I, twisted and untwisted dabco molecules are fully disordered. In the Phase II, the crystal structure is built of the chains of dabco molecules, some of which are composed only of untwisted forms and other only of twisted forms. In Phase III, the twisting of dabco enantiomers is expected to be hindered. Finally, when the interaction between the chains becomes prevailing, the crystal structure is supposed to be chirally ordered in Phase IV.

Note that according to a recent study of $\left[\mathrm{Zn}_{2}\left(\mathrm{C}_{8} \mathrm{H}_{4} \mathrm{O}_{4}\right)_{2} \bullet \mathrm{C}_{6} \mathrm{H}_{12} \mathrm{~N}_{2}\right]$ properties, the Phase $\mathrm{II} \rightarrow$ Phase I transition can be interpreted as an order-disorder phase transition associated with some structural disorder of $\mathrm{C}_{8} \mathrm{H}_{4} \mathrm{O}_{4}{ }^{2-}$ anions $^{12}$. However, dabco molecules remain dynamically disordered and their role in the phase transition is not defined.

Thus, in our opinion, metal-organic framework compound $\left[\mathrm{Zn}_{2}\left(\mathrm{C}_{8} \mathrm{H}_{4} \mathrm{O}_{4}\right)_{2} \bullet \mathrm{C}_{6} \mathrm{H}_{12} \mathrm{~N}_{2}\right]$ and related crystals ${ }^{10-12,31}$ containing racemic mixtures of chiral molecules are convenient systems to develop the approaches aimed at controlling molecular transitions from racemic to chirally polarized states. A special feature of these systems is the absence of direct contacts between chiral molecules in crystals. Such systems are interesting in terms of studying the stabilization of chiral molecules in solids at low temperatures and can serve as models for the conditions of the cold scenario of life origin on the Earth ${ }^{7}$.

\section{Methods}

Heat capacity was measured at 8.98-299.57 K using a computerized vacuum adiabatic calorimeter well tested by measurements of various compounds including sorbents metal-organic framework compound $\left[\mathrm{Zn}_{2}\left(\mathrm{C}_{8} \mathrm{H}_{4} \mathrm{O}_{4}\right)_{2} \bullet \mathrm{C}_{6} \mathrm{H}_{12} \mathrm{~N}_{2}\right]$. The details of the synthesis, experimental conditions, and heat capacity values can be found in work ${ }^{17}$. The ${ }^{1} \mathrm{H}$ NMR spin-lattice relaxation time $\mathrm{T}_{1}$ of $\left[\mathrm{Zn}_{2}\left(\mathrm{C}_{8} \mathrm{H}_{4} \mathrm{O}_{4}\right)_{2} \bullet \mathrm{C}_{6} \mathrm{H}_{12} \mathrm{~N}_{2}\right]$ was measured with a Bruker SXP 4-100 device at 8-300 K and was previously analyzed in a number of works ${ }^{14-16}$.

\section{References}

1. Liu, M., Powell, D. A., Shadrivov, I. V., Lapine, M. \& Kivshar, Y. S. Spontaneous chiral symmetry breaking in metamaterials. Nat. Commun. 5, 4441 (2014).

2. Salam, A. The role of chirality in the origin of life. J. Mol. Evol. 33, 105-113 (1992).

3. Salam, A. Chirality, phase transitions and their induction in amino acids. Phys. Lett. B. 288, 153-160 (1992).

4. Castellan, J.-P. et al. Chiral phase transition in charge ordered 1T-TiSe ${ }_{2}$. Phys. Rev. Lett. 110, 196404 (2013). 
5. Tanaka, Y. et al. Determination of structural chirality of berlinite and quartz using resonant $\mathrm{x}$-ray diffraction with circularly polarized x-rays. Phys. Rev. B. 81, 144104 (2010).

6. Crick, F. Life Itself (Simon and Schuster, NY, 1981).

7. Gol'danskii, V. I. \& Kuz'min, V. V. Spontaneous breaking of mirror symmetry in nature and the origin of life. Soviet Physics Uspekhi. 32(1), 1-29(1989).

8. Wang, W. et al. Parity violation of electroweak force in phase transitions of single crystals of D-and L-alanine and valine. Biol. Phys. 26, 51-65 (2000).

9. Sullivan, R. et al. Search for electroweak interactions in amino acid crystals. II. The Salam hypothesis. J. Phys. Chem. A. 107, 6674-6680 (2003).

10. Seki, K. Design of an adsorbent with an ideal pore structure for methane adsorption using metal complexes. Chem. Commun. 1496-1497 (2001).

11. Dybtsev, D. N., Chun, H. \& Kim, K. Rigid and flexible: A highly porous metal-organic framework with unusual guest-dependent dynamic behavior. Angew. Chem. Int. Ed. 43, 5033-5036 (2004).

12. Kim, Y., Haldar, R., Kim, H., Koo, J. \& Kim, K. The Guest-Dependent Thermal Response of the Flexible MOF $\mathrm{Zn}_{2}(\mathrm{BDC})_{2}(\mathrm{DABCO})$. Dalton Trans. 45, 4187-4192 (2016)

13. Nizovtsev, A. S., Ryzhikov, M. R. \& Kozlova, S. G. Structural flexibility of DABCO. Ab initio and DFT benchmark study. Chem. Phys. Lett. 667, 87-90 (2017).

14. Gabuda, S. P., Kozlova, S. G., Samsonenko, D. G., Dybtsev, D. N. \& Fedin, V. P. Quantum rotations and chiral polarization of qubit prototype molecules in a highly porous metal-organic framework: ${ }^{1} \mathrm{H}$ NMR T 1 study. J. Phys. Chem. C. 115, 20460-20465 (2011).

15. Gabuda, S. P. \& Kozlova, S. G. Chirality-related interactions and a mirror symmetry violation in handed nano structures. J. Chem. Phys. 141, 044701 (2014)

16. Gabuda, S. P. \& Kozlova, S. G. Abnormal difference between the mobilities of left- and right-twisted conformations of $\mathrm{C}_{6} \mathrm{H}_{12} \mathrm{~N}_{2}$ rotosymmetrical molecules at very low temperatures. J. Chem. Phys. 142, 234302 (2015).

17. Paukov, I. E., Samsonenko, D. G., Pischur, D. P., Kozlova, S. G. \& Gabuda, S. P. Phase transitions and unusual behavior of heat capacity in layered high-porous metal organic framework compound. J. Solid State Chem. 220, 254-258 (2014).

18. Abragam, A. The principles of nuclear magnetism. (Oxford University Press, NY, 1961).

19. Bloembergen, N., Purcell, E. M. \& Pound, R. V. Relaxation effects in nuclear magnetic resonance absorption. Phys. Rev. 73, 679-712 (1948).

20. Kozlova, S. G. Behavior of the heat capacity at second-order phase transitions in the $\left[\mathrm{Zn}_{2}\left(\mathrm{C}_{8} \mathrm{H}_{4} \mathrm{O}_{4}\right)_{2} \cdot \mathrm{C}_{6} \mathrm{H}_{12} \mathrm{~N}_{2}\right]$ metal-organic framework compound. JETP Lett. 104, 253-256 (2016).

21. Koksalt, F., Rossler, E. \& Sillescu, H. Spin-lattice relaxation by tunnelling motions of methyl groups in four acetates. J. Phys. C: Solid State Phys. 15, 5821-5827 (1982).

22. Latanowicz, L. \& Filipek, P. Tunneling molecular dynamics in the light of the corpuscular-wave dualism theory. J. Phys. Chem. A 111, 7695-7702 (2007).

23. Williams, T., Pitcher, R. G., Bommer, P., Gutzwiller, G. \& Uskokovic, M. Diastereomeric solute-solute interactions of enantiomers in achiral solvents. Nonequivalence of the nuclear magnetic resonance spectra of racemic and optically active dihydroquinine. J. Am. Chem. Soc. 91, 1871-1872 (1969).

24. Kabachnik, M. I. et al. An NMR study of optical isomers in solution. Tetrahedron. 32, 1719-1728 (1976).

25. Vardi, A. On the role of intermolecular interactions in establishing chiral stability. J. Chem. Phys. 112, 8743-8746 (2000).

26. Sabylinskii, A. V., Gabuda, S. P., Kozlova, S. G., Dybtsev, D. N. \& Fedin, V. P. ${ }^{1}$ NMR refinement of the structure of the guest sublattice and molecular dynamics in the ultrathin channels of $\left[\mathrm{Zn}_{2}\left(\mathrm{C}_{8} \mathrm{H}_{4} \mathrm{O}_{4}\right)_{2} \bullet\left(\mathrm{C}_{6} \mathrm{H}_{12} \mathrm{~N}_{2}\right)\right] n\left(\mathrm{H}_{3} \mathrm{C}\right)_{2} \mathrm{NCHO}$ J. Struct. Chem. 50, 421-428 (2009).

27. Khudozhitkov, A. E., Kolokolov, D. I., Stepanov, A. G., Bolotov, V. A. \& Dybtsev, D. N. Metal-cation-independent dynamics of phenylene ring in microporous MOFs: A ${ }^{2} \mathrm{H}$ solid-state NMR study. J. Phys. Chem. C. 119, 28038-28045 (2015).

28. Gallyamov, M. R., Moroz, N. K. \& Kozlova, S. G. NMR Line shape for a rectangular configuration of nuclei. Appl Magn Reson. 41, 477-482 (2011).

29. Gopalan, V. \& Litvin, D. B. Rotation-reversal symmetries in crystals and handed structures. Nature Mater. 10, 376-381 (2011).

30. VanLeeuwen, B. K., Gopalan, V. \& Litvin, D. B. Double antisymmetry and the rotation-reversal space groups. Acta Crystallogr. Sect. A. 70, 24-38 (2014).

31. Gotoh, K. et al. Arrangement and dynamics of diamine, etheric, and tetraalkylammonium intercalates within graphene or graphite oxide galleries by ${ }^{2} \mathrm{H}$ NMR. J. Phys. Chem. C. 119, 11763-11770 (2015).

\section{Acknowledgements}

This study was financially supported by the Russian Science Foundation (Grant No. 16-12-10016).

\section{Author Contributions}

Svetlana G. Kozlova did an analysis of the data on the specific heat and a comparison with the NMR data. Svyatoslav P. Gabuda explained the NMR data and proposed a model of the mirror symmetry violation of dabco molecules in the metal-organic framework compound.

\section{Additional Information}

Competing Interests: The authors declare that they have no competing interests.

Publisher's note: Springer Nature remains neutral with regard to jurisdictional claims in published maps and institutional affiliations.

(c) Open Access This article is licensed under a Creative Commons Attribution 4.0 International

License, which permits use, sharing, adaptation, distribution and reproduction in any medium or format, as long as you give appropriate credit to the original author(s) and the source, provide a link to the Creative Commons license, and indicate if changes were made. The images or other third party material in this article are included in the article's Creative Commons license, unless indicated otherwise in a credit line to the material. If material is not included in the article's Creative Commons license and your intended use is not permitted by statutory regulation or exceeds the permitted use, you will need to obtain permission directly from the copyright holder. To view a copy of this license, visit http://creativecommons.org/licenses/by/4.0/.

(C) The Author(s) 2017 